\title{
Can a transgender person be an occupational diver? Demonstration from a case report
}

\author{
Richard Pougnet $^{1,2,3}$, Brice Loddé ${ }^{1,3,4}$, Anne Henckes ${ }^{1,5}$, \\ Jean-Dominique Dewitte ${ }^{1,3,6}$, Laurence Pougnet ${ }^{1,7}$ \\ ${ }^{1}$ French Society of Maritime Medicine, France \\ ${ }^{2}$ Dpartment of Philosophy, European University of Brittany, France \\ ${ }^{3}$ Medical Centre for Occupational and Environmental Diseases, University Hospital, Brest, France \\ ${ }^{4}$ Biology Department, European University of Brittany, Brest, France \\ ${ }^{5}$ Centre of Hyperbaric Medicine, University Hospital, Brest, France \\ ${ }^{6}$ Sociology Department, European University of Brittany, Brest, France \\ ${ }^{7}$ Medcial Laboratory, Military Hospital Clermont-Tonnerre, Brest, France
}

\begin{abstract}
This is the first case report about a transgender professional diver. The purpose of this article is to show the professional adaptations to help him to continue occupational dive and to raise the question of the impact on diving risks of hormonal treatment in this case. He was a 39-year-old man when he began his transition. He had worked as a diver for 9 years before his transition. When he changed to look like a woman, there were a few difficulties in continuing his professional activity. The main difficulty was that he looked like a woman while working with men. Modesty was a crucial issue in the enterprise. There were other problems such as the organisation of premises, the physical workload and the interaction between treatments and diving. There is a lack of a law to guide the employer. French legislation does not address the issue of transsexuals for this profession. The medical recommendations do not specify contraindications or adaptations for diving safely. Because of his transition, he lost muscle mass. The occupational physician helped to adjust his activity: decreasing the weight of his diving suit, creating a female-like locker room etc. Finally, the question of the risk of decompression illness arose. Legal hormonal medication seems not to significantly increase the risk of decompression illness, but this diver was taking illicit treatment to speed up the transition. The occupational physician recommended taking the legal hormonal medication.
\end{abstract}

(Int Marit Health 2017; 68, 4: 211-214)

Key words: diving, occupational health, transgender persons

\section{INTRODUCTION}

In France, the exercise of professional diving has been regulated by law since 1991 [1]. Divers must have a medical certificate in order to have the right to work. Hyperbaric exposure requires strengthened medical supervision.

In 2016, new professional recommendations were developed [2]. A yearly medical check is still recommended but medical examinations are less numerous than before. Respiratory and cardiac explorations are performed according to age and sex. As in most medical legislation, these medical recommendations are based on a binary (i.e., male/female) gender framework [3]. Health standards are adapted according to sex. Women and men do not have the same constraints. But which are the health standards for transsexual persons to be an occupational diver?

In this case-report, we describe the case of a professional diver, in transition from male to female (MtF). At present, this person's civil status is still officially male, whereas he is becoming a transgender look-like woman. In the absence of a specific law, and professional recommendations aside, how can a transgender person remain a professional diver in France $[1,2,4]$ ? According to our knowledge, there is as yet

Dr. Richard Pougnet, Centre of Occupational and Environmental Diseases, Teaching Hospital of Brest, 117bis, rue Jules Lesven, 29200 Brest, France, tel: 33601964928 e-mail: richard.pougnet@live.fr 
no article dealing with diving in transgender people on Medline ${ }^{\odot}$. Yet, the prevalence of MtF is increasing because of development of new treatments (hormone, surgery etc.) [5]. It is estimated to be near 1 on 25,000 people [6]. The object of this article is therefore to discuss how a professional diver can remain in professional activity during and after such a transition.

\section{CASE REPORT}

He was a 41-year-old MtF transgender person. His transition began 2.5 years ago. His medical story was sport traumas (fracture of the clavicle, ribs fracture) and attacks of gout. He hadn't received any medical treatment. He smoked 20 cigarettes a day, and drank beer and rum occasionally (around 15 units of alcohol a week). His weight was $100 \mathrm{~kg}$ and his tall was $1.80 \mathrm{~m}$. He had used cocaine a few years ago on Saturday nights before his transition. He was making his transition on his own, through processing purchases on the black market (the Boulogne Hood, Paris) thanks to his relationships and his involvement in the sex trade. He used a treatment called 'Brazilian hormone'. It was contraceptive from Brazil, not allowed in France.

On a professional level, he had been a professional diver for 11 years working in teams of 3 divers. The teams worked all over France, transporting their equipment by van. They slept in hotels during the week and went home on weekends. The main types of work were the inspection and repair of small port facilities: desilting, cleaning with hydraulic brushes, welding etc. He worked with sometimes heavy equipment, such as lances. The difficulty was then to get it into and out of the water because of the weight of the equipment. They also regularly checked nuclear power plants: external controls to collect samples, or to clean pipelines. Sometimes a few specially trained divers had control over the nuclear facilities themselves. Finally, they worked regularly in sewage treatment plants and chemical plants to clean the pipes. In both such cases, special, completely watertight diving suits were used. The equipment weighed more than $50 \mathrm{~kg}$.

The beginning of the transition did not raise any problems. He had mentioned it to no-one, neither his colleagues nor his family, because the transition was not visible and he did his usual job. After a while, he changed his appearance: gynecomastia, loss of muscles etc. He first talked to the doctor who followed the divers. The doctors classed him as female staff, and helped him to claim his new condition within the company. In French law, there is no class for transgender persons. It is why it was considered preferable to consider him as a woman.

This meant it became necessary to change his work tasks. Indeed, French legislation prohibits women from wearing weights of more than $25 \mathrm{~kg}$. In consequence, the company gave him activities that were legal for women workers. In particular, due to the weight of the material, he was no longer given work in chemical factories.

For the sake of modesty, the company, on the advice of the occupational physician, opted for a modification of premises and organisation. The company set up a small adjoining room as a locker room for him. In terms of social inclusion, the intervention of the head of the company and the representatives of the staff must be emphasized. They reminded all of their employees of anti-discrimination laws in France. They sensitized employees in order to avoid all forms of discrimination: derogatory remarks, jokes, etc.

To date, this transgender person continues his professional activity with a specific medical follow-up.

\section{DISCUSSION}

This is the first case of a transgender professional diver in literature.

The hyperbaric physician has to evaluate the risk of decompression illness (DCl) [7]. The diver being a man, one can think that risk of $\mathrm{DCl}$ was the same than before transition. But, the diver took treatment to become an MtF transgender person. Pathophysiological studies have shown that the main mechanism is the formation of bubbles [8]. This would be favoured by biochemical factors, such as nitric oxide synthase deficiency [9]. DCl starts with formation and growth of inert gas bubbles, that have mechanical, embolic and biochemical effects. The main biological effect is an endothelial damage with platelet activation and deposition, inflammatory reaction with leucocyte adhesion and capillary leak [10]. Age, aerobic fitness and adiposity seem to increase the bubble formation after a dive [11]. The impact of other individual characteristic or medication is not well-known. In particular the risk associated with the female sex is controversial: Boussuges et al. [12] observed fewer circulating bubbles in premenopausal women (without difference with or without hormonal contraception) than in men and this difference disappeared in the post-menopausal women (who did not take any hormonal substitution).

This issue of $\mathrm{DCl}$ can be questioned because MtF transgender individuals may elect to undergo hormone replacement therapy (HRT) to maintain secondary female characteristics. MtF transgender people who undergo HRT receive androgen blockers, oestrogen, and progesterone. Androgen blockers can be spironolactone or finasteride or dutasteride. Oestrogens is oestradiol, oral or sublingual, or transdermal or intramuscular. Progesterone can be medroxyprogesterone acetate or micronized progesterone [13]. There are variations in practice according countries [14]. This HRT increased risk of some diseases, such as cancer [15]. For example, prevalence of breast neoplasm among MtF may be higher after HRT, probably because of exposure of exogenous oestrogen [16]. Another example, HRT is associated 
with the potential for worsening cardiovascular disease risk factors (such as blood pressure elevation, tobacco etc.) [13].

There is no data about $\mathrm{DCl}$ among transgender persons, so that in this case, we considered his treatments like contraception treatments among women. Data from the literature also shows a greater prevalence of $\mathrm{DCl}$ among women [17]. Some authors have thus argued that it was because of menstruation and contraceptive treatment. Indeed, contraceptives increase the venous embolic risk and arterial embolic risk $[18,19]$. If indeed contraceptives do increase risk of $\mathrm{DCl}$, it would be dangerous to let him dive. Fortunately, the available data show no link between $\mathrm{DCl}$ and the various contraceptives [12]. The possible link between contraception and $\mathrm{DCl}$ is therefore very controversial. For this diver, a priori, there was therefore no medical contraindication against diving. It should be borne in mind, however, that the embolic risk is increased among transgender people [20]. The physician should be vigilant and stay informed of scientific advances in this regard.

The subject of this article took oestrogens in greater doses. As a result it was difficult to evaluate the risk of $\mathrm{DCl}$. The first solution would be for the diver to take only treatments that are authorised for use in France. In addition the work tasks should be modified, reducing the number of dives with high $\mathrm{DCl}$ risk such as saturation dives and/or dives involving high levels of muscular effort. For example, break periods could be introduced after dives and mechanical handling equipment used to avoid strenuous physical effort during the critical moments of high DCl risk. It would also be appropriate to reducing cardiovascular risk factors such as smoking and obesity.

On one hand, this diver had actually lost muscle mass. On the other hand, the use of high-dose hormonal treatments can have an impact on the bone health of transgender people [21]. However, diving showed the same effect in women, due to an estrogenic stimulation [22]. It therefore seemed advisable to reduce the physical stress during dives. Other types of bone disease prevention measures should, of course, be taken for transgender persons, such as dietary supplements or drug treatments. Some studies have shown that this population does not have a great knowledge of this problem [23]. Information must therefore be provided.

The diving profession is very largely male. Most often, women divers work as scientists or as veterinarians and animal caregivers. The physical constraints are then less important: lower frequency of dives, lower depths. In professional settings, it is very rare to see women diving for high-level technical work, or during saturation diving. For this company, he was the first person considered to be like a woman while employed as a diver. In consequence, the question of decency was raised. There was no adapted cloakroom. The premises were modified to respect the decency of each diver. At the same time, one can ask the question of the balance of the group. The psychoanalytic theories on group dynamics show that, in order to defend themselves from fears related to occupational risks, the groups constitute themselves on an unconscious series of reciprocal tests. This is called the work defensive ideology [24]. This clinical case does not make it possible to know how the divers will react in the long run. Will there be a phenomenon of rejection? Or will the group maintain its cohesion? The literature shows above all the improvement of the well-being at work of transgender people after revelation of their gender. But there is no giving on other workers.

Finally, what should be the follow up for this diver? He can develop pathologies because of diving, but also because of his hormonal treatments. In France, dive monitoring mainly covers respiratory and cardiac functions, and ear, nose and throat. The recommendations for the follow-up of the transgender persons are: haemoglobin, glycaemia, lipidaemia, levels of HRT in blood, and, if necessary, other balance, as prolactinaemia if symptoms appear. These blood tests should be performed every 3 months [13]. In consequence, this diver should have a medical follow-up. The maritime physician and the general practitioner must work together. After surgery, he would be at risk to develop cardiovascular diseases because of testosterone decrease. Transgender medicine is new, but there is a real thinking about guidelines [25, 26]. In France, transgender persons have the right to get free treatments. Gender dysphoria treatment costs are covered by the French national health insurance system. This right is still little known. This implies multidisciplinary care: follow up by an endocrinologist, a psychiatrist, sometimes with a psychologist, before being entitled to a surgical intervention. This may seem constraining but prevents transgender patients from taking potentially dangerous treatments. It also helps them to get out of a relational net that can cause them to become sex workers or to consume drugs, as it was the case for this diver [27]. It also makes it possible to detect and prevent sexually transmitted diseases and enables good advice to be provided on medical follow-up [28]. This is important as treatments are technically complex and can lead to important ethical questions [29].

\section{CONCLUSIONS}

To our knowledge, this is the first reported case of a transgender person working as a professional diver. Adjustments to the work post were necessary to enable this diver to continue professional activity. These adaptations were facilitated by the intervention of the occupational physician within the company, as well as by the good will of the management. Adaptations took into account changes in physical abilities, the need for medical follow-up, as well as questions of physical change and modesty. 


\section{REFERENCES}

1. Pougnet R, Costanzo LDi, Loddé B, et al. Cardiovascular risk factors and cardiovascular risk assessment in professional divers. Int Marit Health. 2012; 63(3): 164-169, indexed in Pubmed: 23129099.

2. Lodde B, Meliet JL, Pougnet R, et al. Recommandations de bonne pratique pour le suivi en santé au travail des travailleurs exposés aux contraintes hyperbares. Arch Mal Pro Env. 2016; 77(3): 414, doi: 10.1016/j.admp.2016.03.131.

3. Eckstrand KL, Ng H, Potter J. Affirmative and Responsible Health Care for People with Nonconforming Gender Identities and Expressions. AMA J Ethics. 2016; 18(11): 1107-1118, doi: 10.1001/journalofethics.2016.18.11.pfor1-1611, indexed in Pubmed: 27883302.

4. Pougnet $R$, Uguen $M$, Verdier $G$, et al. Predicted nine-year risk of diabetes among professional divers: a prospective study. Int Marit Health. 2015; 66(2): 87-92, doi: 10.5603/IMH.2015.0021, indexed in Pubmed: 26119678.

5. Gaither TW, Awad MA, Osterberg EC, et al. Postoperative Complications following Primary Penile Inversion Vaginoplasty among 330 Male to Female Transgender Patients. J Urol. 2017 [Epub ahead of print]: S0022-S5347, doi: 10.1016/j.juro.2017.10.013, indexed in Pubmed: 29032297.

6. LeBreton M, Courtois F, Journel NM, et al. Genital Sensory Detection Thresholds and Patient Satisfaction With Vaginoplasty in Male-toFemale Transgender Women. J Sex Med. 2017; 14(2): 274-281, doi: 10.1016/j.jsxm.2016.12.005, indexed in Pubmed: 28161082.

7. Pollock NW, Buteau D. Updates in Decompression Illness. Emerg Med Clin North Am. 2017; 35(2): 301-319, doi: 10.1016/j. emc.2016.12.002, indexed in Pubmed: 28411929.

8. Lambrechts K, Balestra C, Theron M, et al. Venous gas emboli are involved in post-dive macro, but not microvascular dysfunction. Eur J Appl Physiol. 2017; 117(2): 335-344, doi: 10.1007/s00421-0173537-9, indexed in Pubmed: 28110355.

9. Wisl ff U, Richardson RS, Brubakk AO. NOS inhibition increases bubble formation and reduces survival in sedentary but not exercised rats. J Physiol. 2003; 546(Pt 2): 577-582, doi: 10.1113/ jphysiol.2002.030338, indexed in Pubmed: 12527743.

10. Vann RD, Butler FK, Mitchell SJ, et al. Decompression illness. Lancet. 2011; 377(9760): 153-164, doi: 10.1016/S01406736(10)61085-9, indexed in Pubmed: 21215883.

11. Carturan D, Boussuges $A$, Vanuxem $P$, et al. Ascent rate, age, maximal oxygen uptake, adiposity, and circulating venous bubbles after diving. J Appl Physiol (1985). 2002; 93(4): 1349-1356, doi: 10.1152/ japplphysiol.00723.1999, indexed in Pubmed: 12235035.

12. Boussuges A, Retali G, Bodéré-Melin M, et al. Gender differences in circulating bubble production after SCUBA diving. Clin Physiol Funct Imaging. 2009; 29(6): 400-405, doi: 10.1111/j.1475097X.2009.00884.x, indexed in Pubmed: 19594770.

13. Streed CG, Harfouch O, Marvel F, et al. Cardiovascular Disease Among Transgender Adults Receiving Hormone Therapy: A Narrative Review. Ann Intern Med. 2017; 167(4): 256-267, doi: 10.7326/ M17-0577, indexed in Pubmed: 28738421.

14. Mamoojee Y, Seal L, Quinton R. Transgender hormone therapy: understanding international variation in practice. Lancet Diabetes Endocrinol. 2017; 5(4): 243-246, doi: 10.1016/S22138587(17)30068-2, indexed in Pubmed: 28340645.

15. Braun H, Nash R, Tangpricha V, et al. Cancer in Transgender People: Evidence and Methodological Considerations. Epidemiol Rev.
2017; 39(1): 93-107, doi: 10.1093/epirev/mxw003, indexed in Pubmed: 28486701.

16. Tongson K, Konovalova V, Dhawan N, et al. Breast Cancer Suspicion in a Transgender Male-to-Female Patient on Hormone Replacement Therapy Presenting with Right Breast Mass: Breast Cancer Risk Assessment and Presentation of a Rare Lesion. Case Rep Oncol Med. 2017; 2017: 5172072, doi: 10.1155/2017/5172072, indexed in Pubmed: 28421153.

17. Robinson TJ. Decompression sickness in women divers. Undersea Biomed Res. 1988; 15(1): 65-66, indexed in Pubmed: 3368996.

18. van Hylckama Vlieg A, Helmerhorst FM, Vandenbroucke JP, et al. The venous thrombotic risk of oral contraceptives, effects of oestrogen dose and progestogen type: results of the MEGA case-control study. BMJ. 2009; 339: b2921, doi: 10.1136/bmj.b2921, indexed in Pubmed: 19679614.

19. Lalude 00. Risk of cardiovascular events with hormonal contraception: insights from the Danish cohort study. Curr Cardiol Rep. 2013; 15(7): 374, doi:10.1007/s11886-013-0374-2, indexed in Pubmed: 23715878.

20. Shatzel JJ, Connelly KJ, DeLoughery TG. Thrombotic issues in transgender medicine: A review. Am J Hematol. 2017; 92(2): 204-208, doi:10.1002/ajh.24593, indexed in Pubmed: 27779767.

21. Van Caenegem E, T Sjoen G. Bone in trans persons. Curr Opin Endocrinol Diabetes Obes. 2015; 22(6): 459-466, doi:10.1097/ MED.0000000000000202, indexed in Pubmed: 26512771.

22. Hwang $\mathrm{H}$, Bae J, Hwang $\mathrm{S}$, et al. Effects of breath-hold diving on bone mineral density of women divers. Joint Bone Spine. 2006; 73(4): 419-423, doi:10.1016/j.jbspin.2005.07.005, indexed in Pubmed: 16626996.

23. Sedlak CA, Roller CG, van Dulmen M, et al. Transgender Individuals and Osteoporosis Prevention. Orthop Nurs. 2017; 36(4): 259-268, doi:10.1097/NOR.0000000000000364, indexed in Pubmed: 28737632.

24. Molinier $P$, Flottes A. Travail et santé mentale : approches cliniques. Travail et Emploi. 2012; 129: 56-61.

25. Reisner SL, Deutsch MB, Bhasin S, et al. Advancing methods for US transgender health research. Curr Opin Endocrinol Diabetes Obes. 2016; 23(2): 198-207, doi: 10.1097/MED.0000000000000229, indexed in Pubmed: 26845331.

26. Deutsch MB, Radix A, Reisner S. What's in a Guideline? Developing Collaborative and Sound Research Designs that Substantiate Best Practice Recommendations for Transgender Health Care. AMA J Ethics. 2016; 18(11): 1098-1106, doi: 10.1001/ journalofethics.2016.18.11.stas1-1611, indexed in Pubmed: 27883301.

27. Hayon R. Gender and Sexual Health: Care of Transgender Patients. FP Essent. 2016; 449: 27-36, indexed in Pubmed: 27731969.

28. Chow JY, Konda KA, Borquez A, et al. Peru's HIV care continuum among men who have sex with men and transgender women: opportunities to optimize treatment and prevention. Int J STD AIDS. 2016; 27(12): 1039-1048, doi: 10.1177/0956462416645727, indexed in Pubmed: 27099168.

29. Costa EM, Mendonca BB. Clinical management of transsexual subjects. Arq Bras Endocrinol Metabol. 2014; 58(2): 188-196, doi: 10.1590/0004-2730000003091, indexed in Pubmed: 24830596. 